\title{
The effectiveness of high-flow nasal cannula during sedated digestive endoscopy: a systematic review and meta-analysis
}

Yu-Xin Zhang ${ }^{1 \dagger}$, Xing-Xiang He ${ }^{2 \dagger}$, Yu-Ping Chen ${ }^{1+}$ and Shuai Yang ${ }^{3^{*}}$ (D)

\begin{abstract}
Background: Studies evaluating the role of high-flow nasal cannula (HFNC) in sedated digestive endoscopy have reported conflicting results. This meta-analysis evaluates the effectiveness of HFNC in patients undergoing digestive endoscopy procedures under sedation.
\end{abstract}

Methods: PubMed, Medline, EMBASE, Cochrane Central Register of Controlled Trials and Web of Science, were searched from inception to 31 July 2021. Only randomized clinical trials comparing HFNC with standard nasal cannula oxygen (SNC) during sedated digestive endoscopy were included. The incidence of hypoxemia was the primary outcome, and the secondary outcome was the percentage of patients who needed airway interventions.

Results: Seven studies that enrolled 2998 patients were included. When compared to SNC, HFNC was associated with a significant reduction in hypoxemia incidence (OR $0.24,95 \% \mathrm{Cl} 0.09$ to 0.64 ) and airway intervention requirements (OR $0.15,95 \% \mathrm{Cl} 0.03$ to 0.69$)$, with both high heterogeneity $\left(I^{2}=81 \%\right.$ and $\left.94 \%\right)$. In subgroup analysis, when hypoxemia was defined as pulse oxygen saturation $\left(\mathrm{SpO}_{2}\right)<90 \%$, low risk of hypoxemia subjects who received HFNC were associated with a significant reduction in hypoxemia incidence (OR $0.02,95 \% \mathrm{Cl} 0.00$ to 0.07 ; heterogeneity $\left.\mathrm{I}^{2}=39 \%\right)$ and airway intervention requirements (OR $0.02,95 \% \mathrm{Cl} 0.01$ to 0.04 ; heterogeneity $\left.\mathrm{I}^{2}=15 \%\right)$. However, in the high risk of hypoxemia subjects, there were no significant differences between the two oxygen administration techniques in both primary (OR $0.81,95 \% \mathrm{Cl} 0.36$ to 1.78 ; heterogeneity $\left.{ }^{2}=0 \%\right)$ and secondary outcomes $(\mathrm{OR} 0.85,95 \% \mathrm{Cl}$ 0.46 to 1.59 ; heterogeneity $I^{2}=0 \%$ ).

Conclusions: Compared to SNC, HFNC not only reduce the incidence of hypoxemia but also reduce the requirements for airway interventions during sedated digestive endoscopy procedures, especially in patients at low risk for hypoxemia. In high risk of hypoxemia patients, there were no significant differences between the two oxygen administration techniques.

Trial registration PROSPERO International prospective register of systematic reviews on 28 July 2021, registration no. CRD42021264556.

Keywords: High-flow nasal cannula oxygen (HFNC), Digestive endoscopy, Sedation, Hypoxemia, Airway intervention

*Correspondence: ys5898@126.com

${ }^{\dagger}$ Yu-Xin Zhang, Xing-Xiang He and Yu-Ping Chen contributed equally to this work

${ }^{3}$ Department of Emergency Intensive Care Unit, Zhuhai People's Hospital

(Zhuhai Hospital Affiliated with Jinan University), 79 Kangning Road, Xiangzhou District, Zhuhai 519000, China

Full list of author information is available at the end of the article

\section{Introduction}

In recent years, the number of digestive endoscopy procedures has extended steadily $[1,2]$. More than fifty percent of digestive endoscopy procedures are performed under sedation, relying on anesthesia services $[3,4]$. The purpose of sedated digestive endoscopy is to 
relieve patient discomfort and anxiety, provide better quality examination and reduce the patient's memory of endoscopy experience [5]. However, using common medications such as benzodiazepines and propofol often leads to respiratory depression, airway obstruction, and subsequent hypoxemia [6]. Severe hypoxemia will interrupt the endoscopic procedure, and require immediate airway interventions, such as chin lift, jaw thrust, nasal airway, mask ventilation, invasive or noninvasive ventilation. Continuous hypoxemia may lead to arrhythmia, myocardial ischemia, permanent neurological complications, or death [7-9].

Administering supplementary oxygen using a standard nasal cannula (SNC) is the current standard of care for most patients undergoing sedation for digestive endoscopy procedures [10]. Usually, the highest oxygen flow SNC can provide is $6 \mathrm{~L} / \mathrm{min}$. Under this circumstance, inspired oxygen concentration $\left(\mathrm{FiO}_{2}\right)$ in the distal airways is no more than $40 \%$ [11]. Higher inspired oxygen concentrations are not possible with SNC, because the patient's inspiratory flow changes with each breath. If the inspiratory flow is greater than the flow of oxygen, then room air is entrained, which lowers the $\mathrm{FiO}_{2}$.

High-flow nasal cannula (HFNC) oxygen is a recently developed non-invasive oxygen therapy system. It can provide heated and moist oxygen through the nasal cannula, as well as offer a much higher and predictable gas flow rate (up $60 \mathrm{~L} / \mathrm{min}$ ) and $\mathrm{FiO}_{2}$ (up to $100 \%)[12,13]$. In HFNC therapy, the high flow also produces positive pressure within the nasopharyngeal space and thoracic cavity [14], which reduces airway obstruction and increases the end-expiratory lung volume [15-18]. Because of its potential to improve oxygenation and ventilation, HFNC has been applied in many clinical situations to prevent hypoxemia, such as in awake fiber-optic intubation [19], conscious sedation during bronchoscopy and some dental treatments under intravenous sedation $[16,20]$. In addition, a few randomized controlled trials have shown that HFNC could also reduce the risk of hypoxemia during sedated digestive endoscopy [21, 22], but some studies cannot draw the same conclusion [23, 24].

Is HFNC more effective than SNC in reducing the incidence of hypoxemia during sedated digestive endoscopy? Research in this area is new, and up to now, there are no established guidelines. The aim of the present study is to investigate whether HFNC has more advantages than SNC in sedated digestive endoscopy, with particular emphasis on the effects of preventing hypoxia as well as avoiding airway interventions.

\section{Materials and methods}

This meta-analysis was conducted in accordance with the Preferred Reporting Items for Systematic Reviews and Meta-Analyses (PRISMA) statement [25]. The protocol of this review was registered on PROSPERO (Registration Number: CRD42021264556). Ethical consent was unnecessary, because the data needed to support the current meta-analysis was derived from previously published studies.

\section{Inclusion and exclusion criteria}

The studies had to meet the following inclusion criteria: be randomized and controlled, compare HFNC with SNC, include adult patients who underwent sedated digestive endoscopy (including endoscopic retrograde cholangiopancreatography, esophagogastroduodenoscopy, gastroscopy, gastrointestinal endoscopy, and colonoscopy). Obstetrics and pediatric patient studies were excluded.

\section{Search strategy}

We searched the following five electronic databases: PubMed, Medline, EMBASE, Cochrane Central Register of Controlled Trials, and Web of Science from inception to 31 July 2021. We used the search terms (High-flow nasal cannula oxygen) AND (digestive endoscopy) AND (sedation) AND (randomized clinical trials), limited to humans and adults where possible (details were shown in Additional file 1). We reviewed the references lists of articles for other studies to supplement our search.

\section{Outcome measures}

The primary outcome was to investigate whether HFNC versus SNC resulted in a different incidence of hypoxemia at any time point during the procedure. The secondary outcome was the percentage of patients who need airway interventions (including chin lift, jaw thrust, nasal airway, mask ventilation, invasive or noninvasive ventilation).

\section{Study selection and data extraction}

Two researchers (Shuai Yang and Yu-Xin Zhang) independently evaluated the title and abstract of RCTs that were probably eligible. Then the full text was extracted, and the eligibility according to the eligibility criteria was assessed. Any dispute was resolved through discussion with a third reviewer (Xing-Xiang He). Data extraction was performed using a self-designed data collection form. It included the study ID, the first author's name and publication year, country, endoscopic method, NCT number, primary and secondary 
outcomes. Subjects would be considered to be of high risk for developing hypoxemia when they were obese (BMI > 30), or had obstructive sleep apnoea syndrome (OSAS), or were American Society of Anesthesiologists (ASA) physical status 3 or 4 . If the subjects were $\mathrm{BMI}<30$, or without OSAS, or were ASA physical status 1 or 2 , the subjects were considered relatively low risk for developing hypoxemia.

\section{Quality assessment}

Using the Cochrane Collaboration Risk of Bias tool, two reviewers (Shuai Yang and Yu-Xin Zhang) independently assessed the methodological quality of the selected studies. Any conflicting opinions were resolved by discussion in the presence of a third investigator (Xing-Xiang $\mathrm{He}$ ). Every included study was assessed for the following sources of bias: selection bias (random sequence generation and allocation concealment), blinding of participants and personnel, blinding of outcome assessment, incomplete outcome data, selective reporting, and other bias.

\section{Data synthesis and analysis}

Statistical analysis of our study was performed with the cochrane systematic review software Review Manager (RevMan, version: 5.4). Odds ratio (OR) with 95\% confidence interval $(95 \% \mathrm{Cl})$ was calculated for the dichotomous outcomes. Heterogeneity was tested by the $\mathrm{I}^{2}$ statistics. When $\mathrm{I}^{2}$ was greater than $50 \%$, a random-effect model was used, while if there was no substantial heterogeneity $\left(\mathrm{I}^{2}<50 \%\right)$, the fixed-effect model was used. Twosided tests were used in all analyses, and $P<0.05$ was considered statistically significant.

\section{Results}

\section{Study search}

Initially, 221 articles were identified (216 were extracted from databases, and 5 were extracted from other sources). After discarding duplicate reports, 59 studies were screened according to their titles and abstracts to determine the possible studies. Finally, the full texts of 14 articles were evaluated, and 7 studies were excluded: 1 was a pediatric patient study, 1 was a comment paper, 3 were protocols, 2 were observational studies. In total, 7 RCTs [21-24, 26-28] were eligible in our meta-analysis, which ultimately included 2998 patients. The flowchart of the study is shown in Fig. 1.

\section{Study characteristics}

The characteristics of individual studies included in this meta-analysis are presented in Tables 1 and 2. These studies were published between 2019 and 2021. Trials took place across North America, Europe, Asia, and Australia. HFNC in two studies was used during ERCP procedural sedation [22, 24], and others were used during esophagogastroduodenoscopy procedural sedation. In 3 of 7 articles, procedures were performed on high risk of hypoxemia subjects [23, 24, 28]. In the other four articles, sedation procedures were performed on low risk of hypoxemia subjects. All studies reported the primary outcome, and 6 of 7 studies reported the secondary outcome $[21-24,26,28]$.

\section{Sources of heterogeneity}

We identified potential sources of clinical heterogeneity. The population included in the studies and the definition of hypoxemia were both sources of clinical heterogeneity. The population included high risk of hypoxemia subjects and relatively low risk of hypoxemia subjects (The definition of risk of hypoxemia had been detailed in the "Study selection and data extraction" section). The definition of hypoxemia varied among studies. Most included hypoxemia diagnosed with $\mathrm{SpO}_{2}<90 \%$ [21-24, 26], two studies included hypoxemia diagnosed with $\mathrm{SpO}_{2}<92 \%[27,28]$. In our subgroup analysis, we included studies in which hypoxemia was defined as $\mathrm{SpO}_{2}<90 \%$.

\section{Quality assessment}

The risk of bias of 7 included RCTs was evaluated based on the Cochrane Handbook. The risk of bias for each article was assessed, and the details of the results are presented in Fig. 2A, B. Because blinding of participants and personnel was impossible in these studies, it might lead to performance bias. Five studies reported appropriate allocation and concealment methods, but two studies did not describe specific strategies [22, 26]. Blinding of outcome assessment was unclear in two studies $[22,26]$, because they did not elaborate any methods to blind outcome assessors from group allocation. In terms of incomplete outcome data, 7 studies were at low risk of bias, for no data were missing. All seven studies had low risk in randomization of sequence generation and selective reporting. Other risk, including potential source of bias was not found in all included studies.

\section{Primary outcomes}

Compared to SNC, HFNC was associated with a significant reduction in hypoxemia incidence during sedated digestive endoscopy (OR 0.24, 95\% CI 0.09 to $0.64, P=0.004 ; \mathrm{M}-\mathrm{H}$ Random; $n=2998$; heterogeneity $\mathrm{I}^{2}=81 \%, P<0.0001$ ) (Fig. 3 ). In subgroup analysis, when hypoxemia was defined as $\mathrm{SpO}_{2}<90 \%$, low risk of hypoxemia subjects who received HFNC were associated with a significant reduction in hypoxemia incidence (OR 0.02 , 95\% CI 0.00 to $0.07, P<0.00001 ; \mathrm{M}-\mathrm{H}$ Fixed; $n=2167$; heterogeneity $\mathrm{I}^{2}=39 \%, P=0.19$ ) (Fig. 4A). However, in the high risk of hypoxemia subjects, there was no 


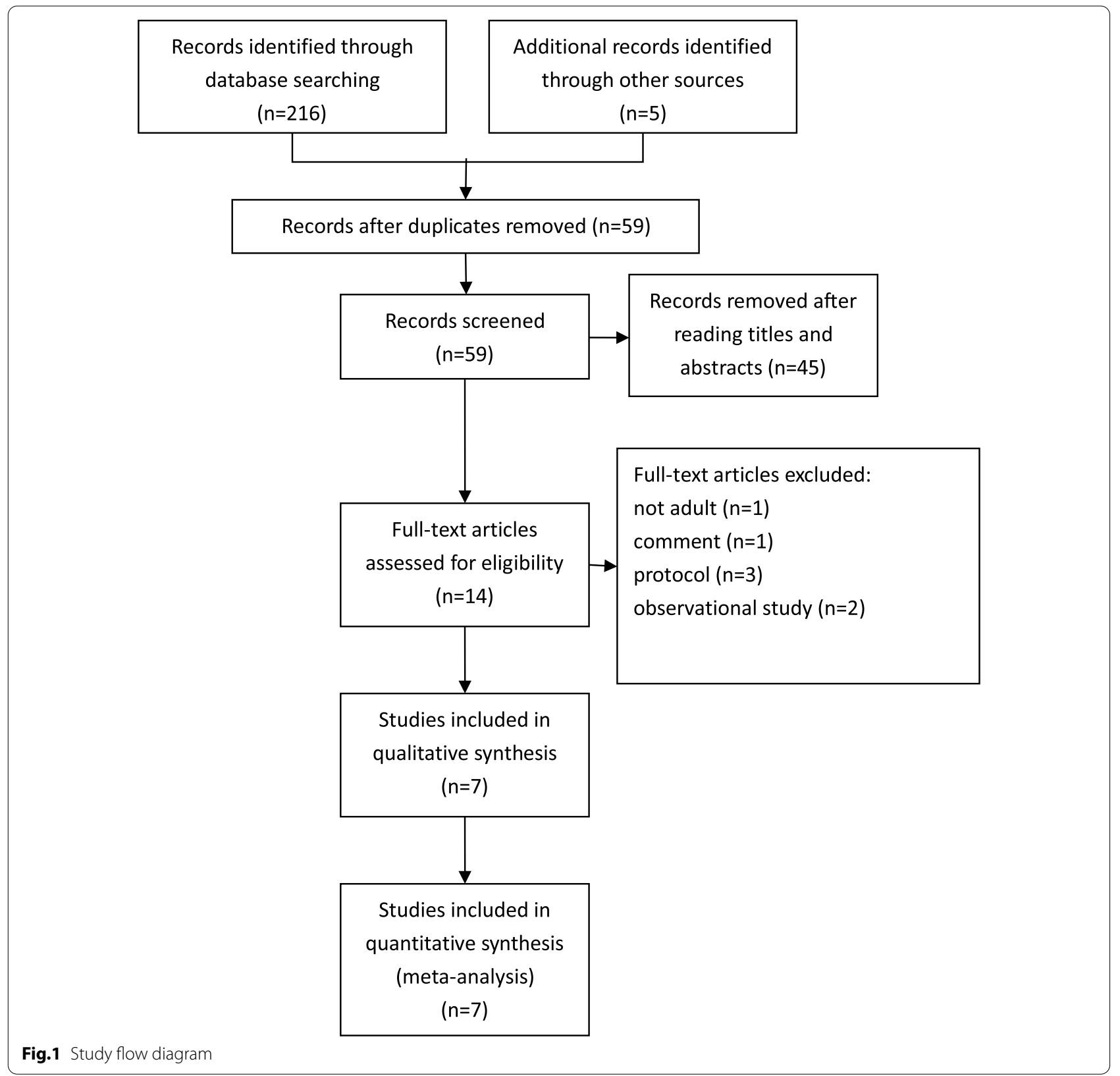

difference between the two groups (OR 0.81, 95\% CI 0.36 to $1.78, P=0.59 ; \mathrm{M}-\mathrm{H}$ Fixed; $n=190$; heterogeneity $\left.\mathrm{I}^{2}=0 \%, P=0.94\right)($ Fig. $4 \mathrm{~B})$.

\section{Secondary outcomes}

When compared to SNC, pooled data suggested that the percentage of patients who need airway interventions during sedated digestive endoscopy was significantly decreased in the HFNC group (OR 0.15, 95\% CI 0.03 to $0.69, P=0.01 ; \mathrm{M}-\mathrm{H}$ Random; $n=2736$; heterogeneity $\mathrm{I}^{2}=94 \%, P<0.00001$ ) (Fig. 5). In subgroup analysis, when hypoxemia was defined as pulse oxygen saturation $\left(\mathrm{SpO}_{2}\right)<90 \%$, low risk of hypoxemia subjects who received HFNC were associated with a significant reduction in airway intervention requirements (OR 0.02, 95\% CI 0.01 to $0.04, P<0.00001$; $\mathrm{M}-\mathrm{H}$ Fixed; $n=2167$; heterogeneity $\mathrm{I}^{2}=15 \% ; P=0.31$ ) (Fig. 6A). However, in the high risk of hypoxemia subjects, there was no difference between the two groups (OR $0.85,95 \%$ CI 0.46 to $1.59, P=0.62$; M-H Fixed; $\mathrm{n}=190$; heterogeneity $\mathrm{I}^{2}=0 \%, P=0.57$ ) (Fig. 6B). 
Table 1 Characteristics of Included Studies

\begin{tabular}{|c|c|c|c|c|c|c|c|}
\hline Author (Year) & NCT No. & Country & Population & Endoscopic method & $\begin{array}{l}\text { Hypoxemia } \\
\text { definition }\end{array}$ & Hypoxemia risk* & Outcome ${ }^{\#}$ \\
\hline Kim 2021 [22] & NCT03872674 & Korea & 72 & ERCP & $\mathrm{SpO}_{2}<90 \%$ & Low & (1)(2) \\
\hline Teng 2019 [26] & NCT03138850 & Taiwan & 101 & $\begin{array}{l}\text { Esophagogastroduo- } \\
\text { denoscopy }\end{array}$ & $\mathrm{SpO}_{2}<90 \%$ & Low & (1)(2) \\
\hline Mazzeffi 2021 [27] & NCT03028688 & America & 262 & $\begin{array}{l}\text { Esophagogastroduo- } \\
\text { denoscopy }\end{array}$ & $\mathrm{SpO}_{2}<92 \%$ & Low & (1) \\
\hline Lin 2019 [21] & NCT03332433 & China & 1994 & Gastroscopy & $\mathrm{SpO}_{2}<90 \%$ & Low & (1)(2) \\
\hline Nay 2021 [28] & NCT03829293 & France & 379 & $\begin{array}{l}\text { Gastrointestinal } \\
\text { endoscopy }\end{array}$ & $\mathrm{SpO}_{2}<92 \%$ & High & (1)(2) \\
\hline Riccio 2019 [23] & NCT03148262 & America & 59 & Colonoscopy & $\mathrm{SpO}_{2}<90 \%$ & High & (1)(2) \\
\hline $\begin{array}{l}\text { Thiruvenkatarajan } \\
2021 \text { [24] }\end{array}$ & CTRN12619000397112 & Australia & 131 & ERCP & $\mathrm{SpO}_{2}<90 \%$ & High & (1)(2) \\
\hline
\end{tabular}

ERCP endoscopic retrograde cholangiopancreatography

*High: patients were obese (BMI > 30), or had obstructive sleep apnoea syndrome, or were ASA physical status 3 or 4; Low: others

\# Outcome include: (1)Hypoxemia; (2)Need for airway interventions

\section{Discussion}

Hypoxemia is the most common negative effect of procedural sedation, and the rate of oxygen desaturation during sedated digestive endoscopy has been reported to be as high as $11-50 \%$ [29]. Although sedation-related mortality in digestive endoscopy is generally rare (about $0.08 \%$ ), the harmful effect of hypoxemia is systemic, and even a short episode of hypoxemia to $\mathrm{SpO}_{2}$ lower than $90 \%$ is related to increased hospital length of stay, intensive care unit admissions and costs [30].

HFNC is a new oxygen administration technique for improving oxygenation and has been applied in many sedation procedures, such as sedated bronchoscopy and dental treatments $[16,20]$. However, the use of HFNC in preventing hypoxemia during sedated digestive endoscopy has not been studied extensively. After our literature search, there are only 7 randomized controlled trials regarding the use of HFNC in digestive endoscopic sedation.

Consistent with previous studies in the sedated bronchoscopy and dental procedures [16, 20], we found that patients receiving HFNC were significantly less likely to desaturate than SNC in adult patients during sedated digestive endoscopy (Fig. 3). We also clarified the beneficial effect of HFNC therapy in reducing the requirement of airway maneuvers during sedation procedures (Fig. 5). We believe that the advantage of HFNC for preventing hypoxemia during sedated digestive endoscopy is mainly reflected in the following two aspects. First, by providing high and constant oxygen flow, HFNC overcomes the issue of room air entrainment [31]. $\mathrm{FiO}_{2}$ is more consistent at higher flows and can be maintained as high as $100 \%[32,33]$. A high fraction of inspired oxygen is undoubtedly helpful for preserving pulse oxygen saturation. However, maintaining a hundred percent fraction of inspired oxygen via a standard nasal cannula is impossible. Even with the highest oxygen flow rate, the maximal $\mathrm{FiO}_{2}$ cannot exceed eighty percent [34]. Second, depending on the high flow, HFNC can flush out the anatomical dead space and supply positive airway pressures without increasing the volume of gastric secretions [35]. These effects facilitate both oxygenation and carbon dioxide clearance during sedation [36], when inspiratory efforts may be somewhat suppressed.

Although the overall hypoxemia incidence and airway intervention requirements of the HFNC group were significantly lower than that of the SNC group, data of the included studies showed high heterogeneity (Primary outcome: $\mathrm{I}^{2}=81 \%$; Secondary outcome: $\mathrm{I}^{2}=94 \%$ ) (Figs. 3, 5). We tried to identify potential sources of clinical heterogeneity and made a subgroup analysis. We found that populations enrolled in these seven studies were different. In three of these articles [37-40], the subjects included were obese (BMI $>30$ ), or had obstructive sleep apnoea syndrome, or were ASA physical status 3 or 4 , which may all contribute to the development of hypoxemia during sedation for gastrointestinal endoscopy. Four other studies enrolled subjects were of relatively low risk for developing hypoxemia, such as with more people $\mathrm{BMI}<30$, or were ASA physical status 1 or 2 . It seems acceptable to explain the heterogeneity from the perspective of hypoxemia risk during digestive endoscopic sedation, because populations with different hypoxemia risks may respond differently to HFNC [23, 41, 42]. Besides, we also note that hypoxemia in these studies was inconsistently defined. Most included hypoxemia defined as a $\mathrm{SpO}_{2}$ of $<90 \%$, and two studies included hypoxemia defined as a $\mathrm{SpO}_{2}$ of $<92 \%$. The $\mathrm{SpO}_{2}$ readings of $90 \%$ 


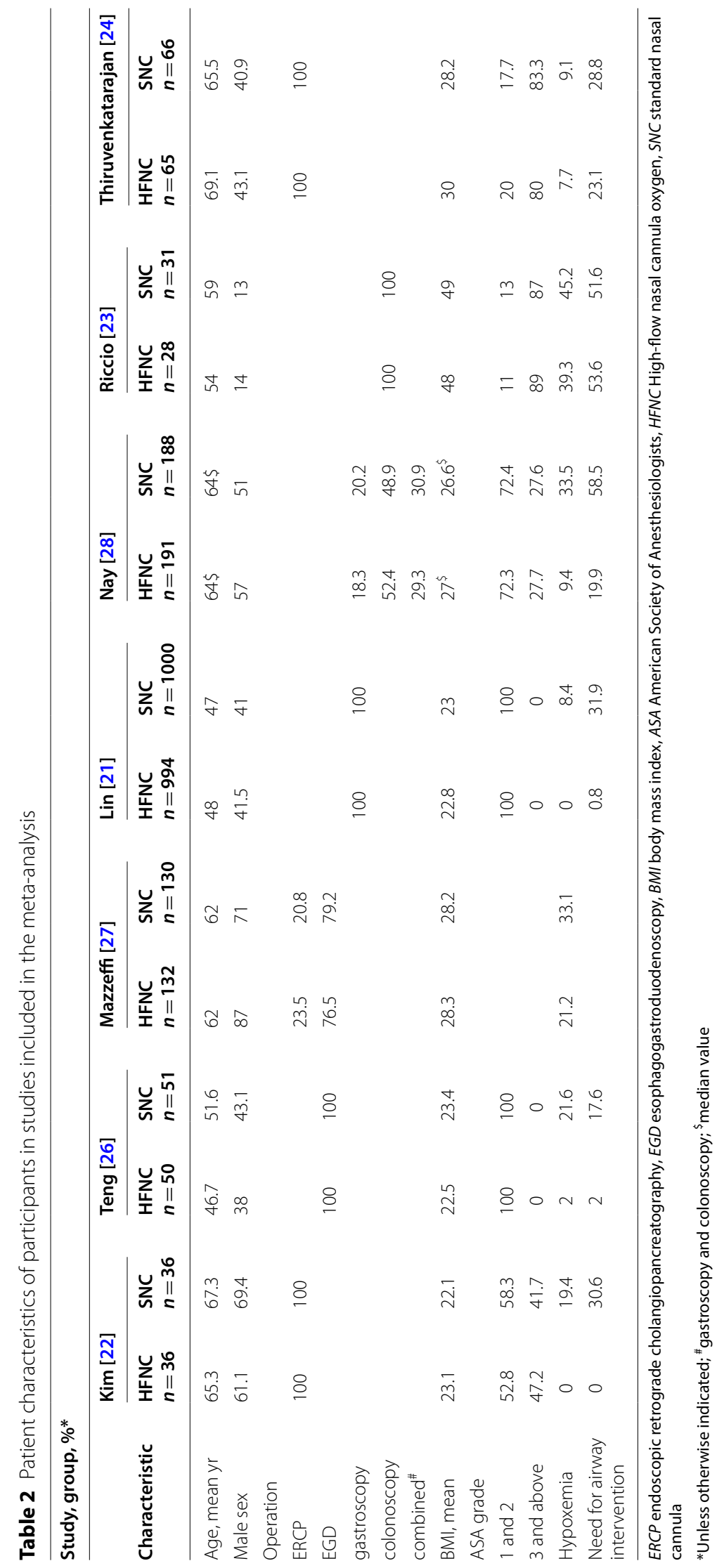




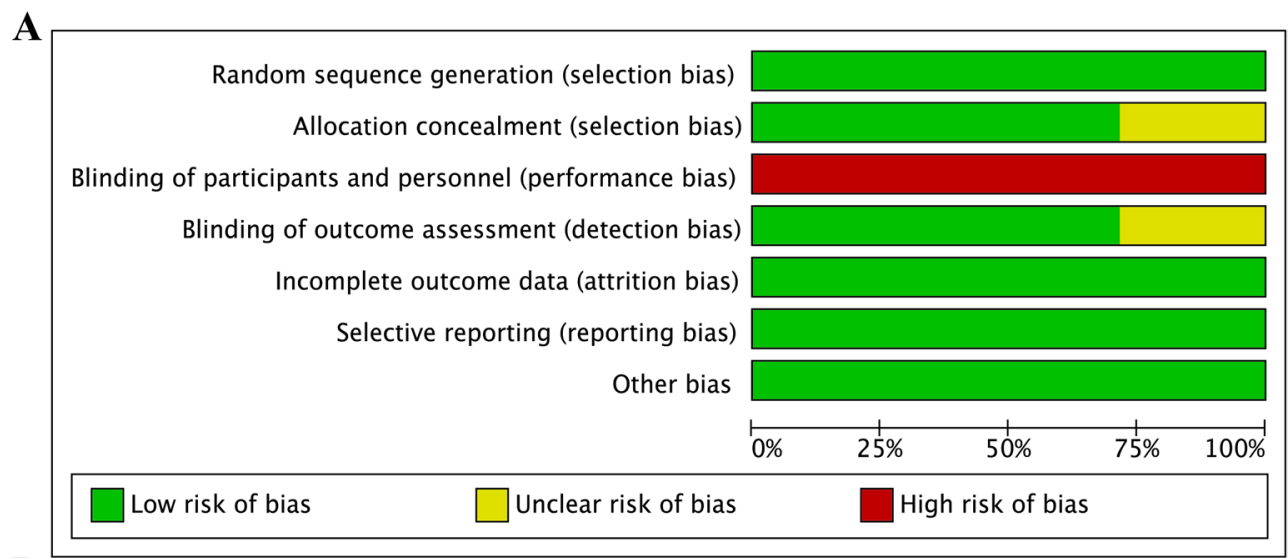

B

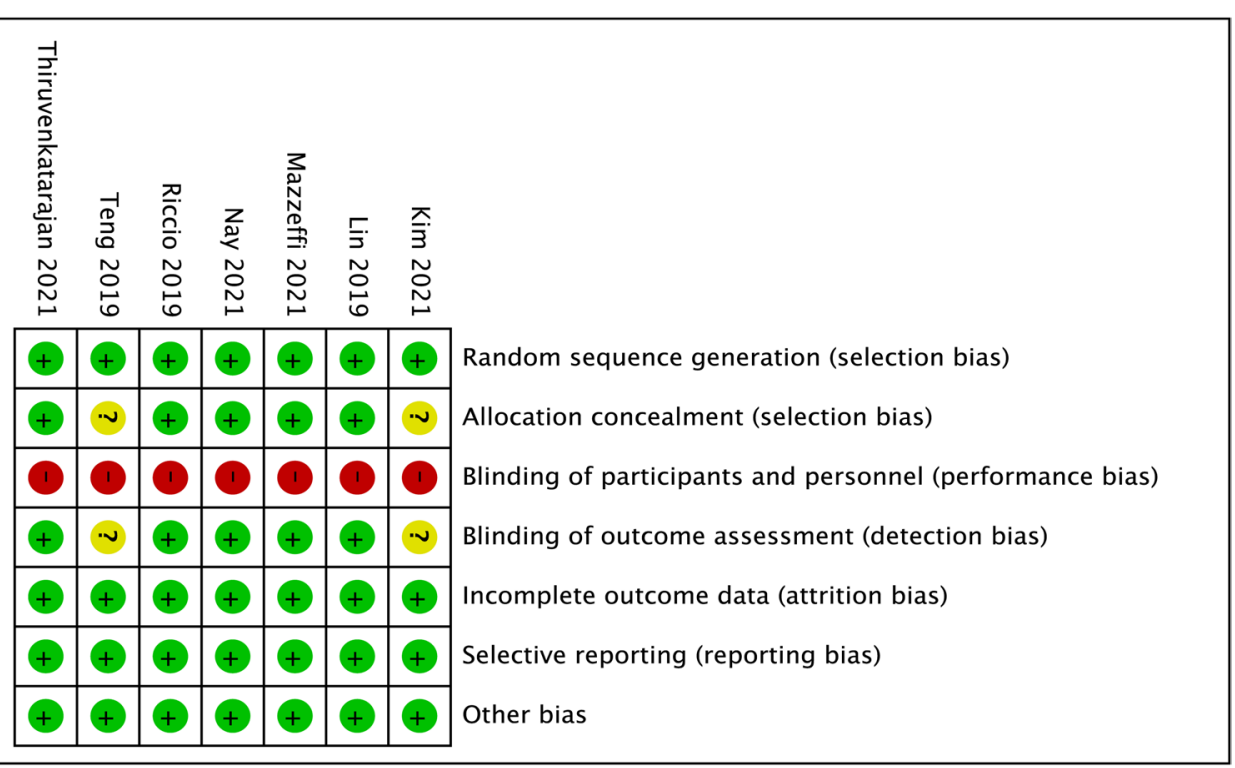

Fig.2 Risk of bias

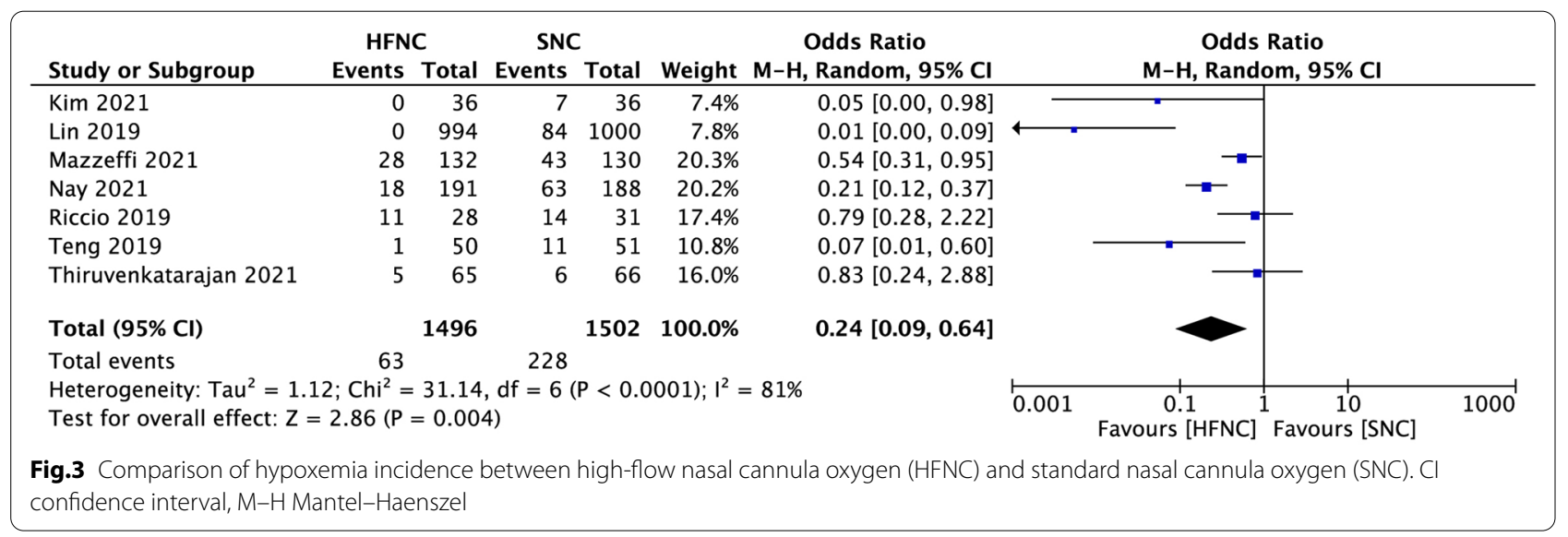




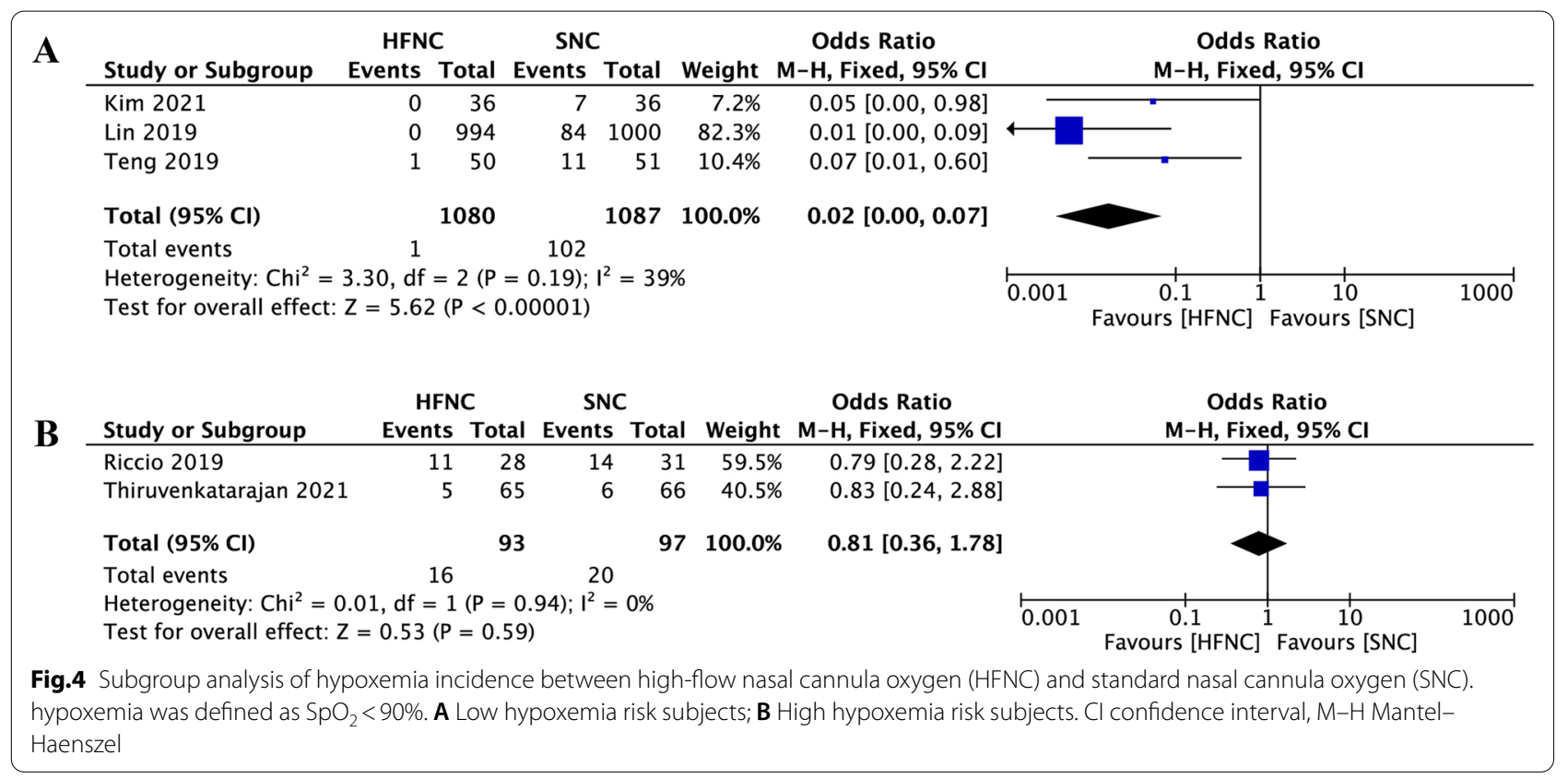

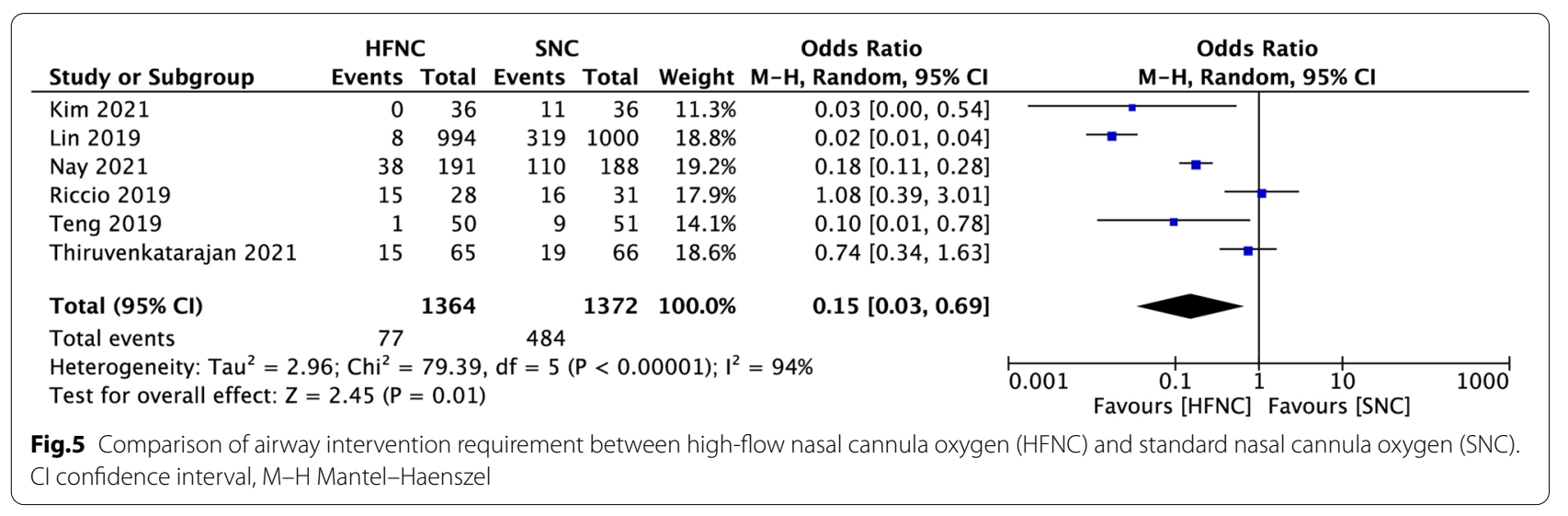

to $94 \%$ are often defined as arterial oxygen desaturation, while a threshold of $\mathrm{SpO}_{2}<90 \%$ is used to define arterial hypoxemia. Different $\mathrm{SpO}_{2}$ thresholds may account for different study results $[43,44]$. Therefore, in our further analysis, we defined hypoxemia as $\mathrm{SpO}_{2}$ lower than $90 \%$, and with that definition, we made a subgroup analysis based on populations with different hypoxemia risks.

In subgroup analysis, compared to SNC, patients at low risk of hypoxemia who received HFNC were associated with a significant reduction in hypoxemia incidence and airway intervention requirements with both low heterogeneities (Figs. 4A and 6A). However, in the high risk of hypoxemia patients who underwent sedated digestive endoscopy, there was no difference between the two supportive oxygen therapy methods in both primary and secondary outcomes with both low heterogeneities (Figs. 4B and $6 \mathrm{~B})$. In the high risk of hypoxemia patients, the effectiveness of HFNC during sedated digestive endoscopy was not superior to the SNC, and there are two possible reasons. First, subjects enrolled in this group were either morbidly obese or with high ASA physical status, and they were more likely to face varying degrees of hypoventilation under sedation [45]. Although HFNC can provide higher $\mathrm{FiO}_{2}$ than $\mathrm{SNC}$, it is unlikely to ameliorate hypoxaemia developing from sedation induced hypoventilation or shunt [16, 46, 47]. Second, to overcome hypoventilation, patients at high risk of hypoxemia often need more positive airway pressures during sedation. With mouth closed and a maximum flow of $60 \mathrm{~L} / \mathrm{min}$, positive airway pressure generated by HFNC therapy may reach up to $5.6 \mathrm{cmH}_{2} \mathrm{O}$ [48]. However, a previous study showed that the conscious patient breathes mostly nasally while 


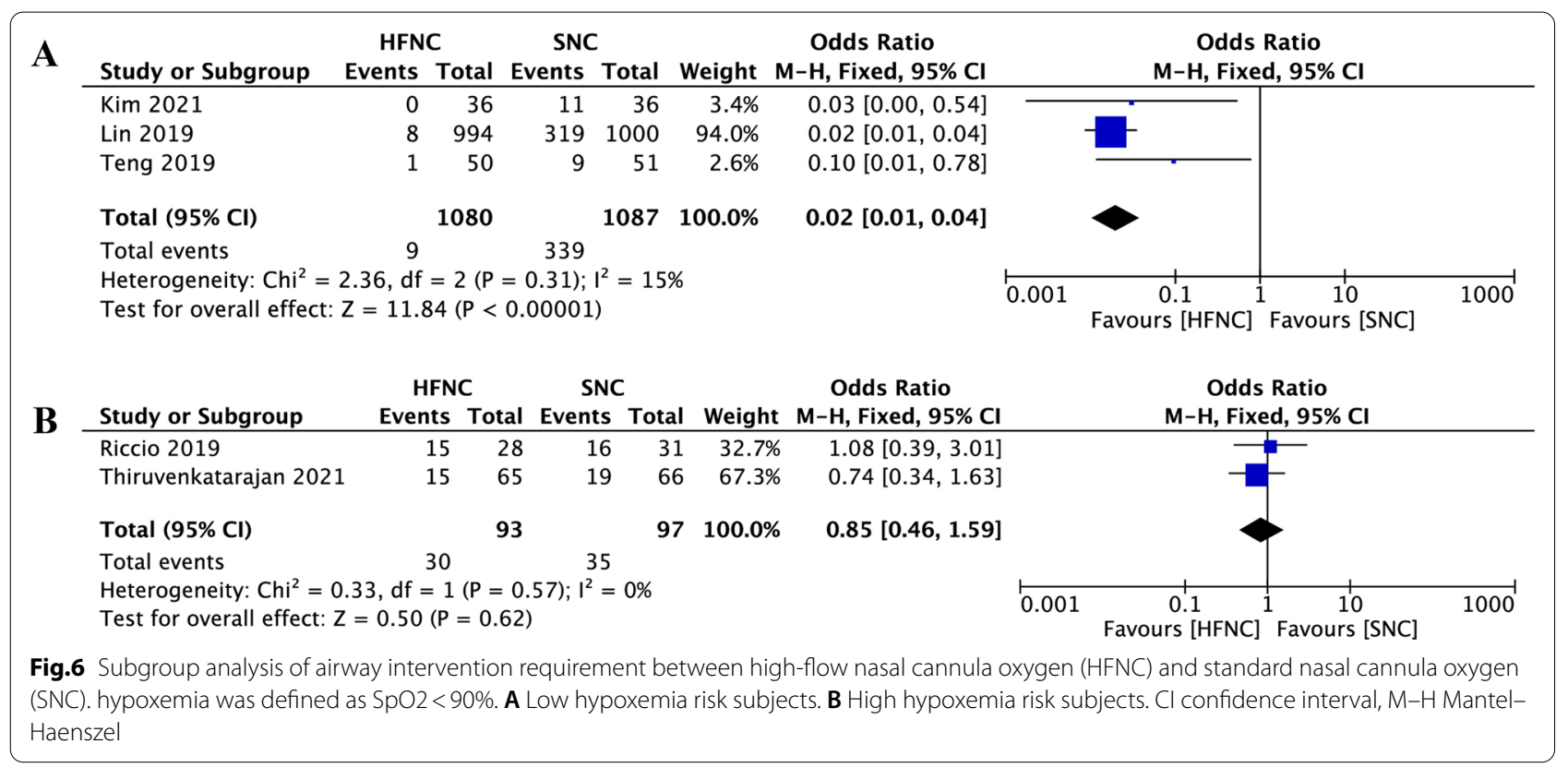

the sedated patient breathes mostly orally during esophagogastroduodenoscopy [49]. The opening of the mouth during digestive endoscopic sedation causes the escape of HFNC gas, which reduces the positive airway pressure to $1.7 \mathrm{cmH}_{2} \mathrm{O}$ [48]. Such a small airway pressure has little effect on preventing hypoxemia in these patients. Therefore, the greatest challenge of providing adequate oxygenation in high-risk patients undergoing sedation is the inability to provide appropriate positive airway pressures. In recent years, by creating new types of masks or ventilation systems, device manufacturers have stepped in to fill this void, and some masks such as endoscopic nasal mask [50] and SuperNO2VA ${ }^{\mathrm{TM}}$ nasal PAP ventilation system [51] had been proven useful in these highrisk patients during sedated digestive endoscopy.

\section{Limitations}

Although this is the first systematic review and metaanalysis evaluating the effects of HFNC in digestive endoscopic procedures under sedation, some limitations of our study need to be noted. First, the flow rate of HFNC, the fraction of inspired oxygen, patient's positioning, sedation agents, the depth of sedation, and duration of endoscopy ranged widely in our enrolled studies, which may further impede the clinical practice. Second, although in the subgroup analysis of high risk of hypoxemia patients, we found HFNC showed no better outcomes, the sample size of included studies was small. More RCTs with large sample size were needed to demonstrate convincing results. Furthermore, in the subgroup analysis of low risk of hypoxemia patients; because of the relatively large sample size, Lin's [21] study may be overpowering the other studies. However, even if it overpowers or is heavily weighted, our meta-analysis or that single study itself still suggest the potential benefit of using HFNC in low-risk patients which decreases the risk of hypoxemia or need for interventions. Third, bias cannot be completely ruled out, because blinding of participants and personnel was impossible.

\section{Conclusions}

This systematic review and meta-analysis suggest that HFNC is more effective than SNC in preventing hypoxemia and avoiding airway interventions during sedated digestive endoscopy, but the subgroup analysis shows that HFNC may be more suitable for patients at low risk of hypoxemia.

\section{Abbreviations}

ERCP: Endoscopic retrograde cholangiopancreatography; EGD: Esophagogastroduodenoscopy; BMI: Body mass index; ASA: American Society of Anesthesiologists; HFNC: High-flow nasal cannula oxygen; SNC: Standard nasal cannula; OR: Odds ratio; Cl: Confidence interval; M-H: Mantel-Haenszel.

\section{Supplementary Information}

The online version contains supplementary material available at https://doi. org/10.1186/s40001-022-00661-8.

Additional file 1: Search strategy.

Acknowledgements

None. 


\section{Authors' contributions}

SY designed research; SY, YXZ conducted research; YPC, XXH analyzed data; SY, YXZ wrote the first draft of manuscript; SY had primary responsibility for final content. All authors read and approved the final manuscript.

\section{Funding}

This work was supported by Zhuhai Health Bureau (Grant Number: 030001QTEC2021LIBD0003).

\section{Availability of data and materials}

All data generated or analyzed during this study are included in this published article.

\section{Declarations}

\section{Ethics approval and consent to participate}

Not applicable.

\section{Consent for publication}

Not applicable.

\section{Competing interests}

The authors declare that they have no competing interests.

\begin{abstract}
Author details
'Department of Gastroenterology, Zhuhai People's Hospital (Zhuhai Hospital Affiliated with Jinan University), Zhuhai 519000, China. ${ }^{2}$ Department of Gastroenterology, The First Affiliated Hospital of Guangdong Pharmaceutical University, Guangzhou 510080, China. ${ }^{3}$ Department of Emergency Intensive Care Unit, Zhuhai People's Hospital (Zhuhai Hospital Affiliated with Jinan University), 79 Kangning Road, Xiangzhou District, Zhuhai 519000, China.
\end{abstract}

Received: 7 November 2021 Accepted: 14 February 2022

Published online: 24 February 2022

\section{References}

1. Shenbagaraj L, Thomas-Gibson S, Stebbing J, Broughton R, Dron M, Johnston D, et al. Endoscopy in 2017: a national survey of practice in the UK. Frontline Gastroenterol. 2019;10(1):7-15.

2. Sidhu R, Turnbull D, Newton M, Thomas-Gibson S, Sanders DS, Hebbar $S$, et al. Deep sedation and anaesthesia in complex gastrointestinal endoscopy: a joint position statement endorsed by the British Society of Gastroenterology (BSG), Joint Advisory Group (JAG) and Royal College of Anaesthetists (RCoA). Frontline Gastroenterol. 2019:10(2):141-7.

3. Vicari JJ. Sedation in the ambulatory endoscopy center: optimizing safety, expectations and throughput. Gastrointest Endosc Clin N Am. 2016;26(3):539-52.

4. Vargo JJ, Niklewski PJ, Williams JL, Martin JF, Faigel DO. Patient safety during sedation by anesthesia professionals during routine upper endoscopy and colonoscopy: an analysis of 1.38 million procedures. Gastrointest Endosc. 2017;85(1):101-8.

5. Trevisani L, Zelante A, Sartori S. Colonoscopy, pain and fears: is it an indissoluble trinomial? World J Gastrointest Endosc. 2014;6(6):227-33.

6. Martin JP, Arlett PA, Holdstock G. Development of a sedation policy for upper $\mathrm{Gl}$ endoscopy based on an audit of patients' perception of the procedure. Eur J Gastroenterol Hepatol. 1996;8(4):355-7.

7. Qadeer MA, Lopez AR, Dumot JA, Vargo JJ. Hypoxemia during moderate sedation for gastrointestinal endoscopy: causes and associations. Digestion. 2011;84(1):37-45.

8. Xiao Q, Yang Y, Zhou Y, Guo Y, Ao X, Han R, et al. Comparison of nasopharyngeal airway device and nasal oxygen tube in obese patients undergoing intravenous anesthesia for gastroscopy: a prospective and randomized study. Gastroenterol Res Pract. 2016;2016:2641257.

9. Patterson KW, Noonan N, Keeling NW, Kirkham R, Hogan DF. Hypoxemia during outpatient gastrointestinal endoscopy: the effects of sedation and supplemental oxygen. J Clin Anesth. 1995;7(2):136-40.
10. Early DS, Lightdale JR, Vargo JJ 2nd, Acosta RD, Chandrasekhara V, Chathadi KV, et al. Guidelines for sedation and anesthesia in Gl endoscopy. Gastrointest Endosc. 2018;87(2):327-37.

11. Lodeserto FJ, Lettich TM, Rezaie SR. High-flow nasal cannula: mechanisms of action and adult and pediatric indications. Cureus. 2018;10(11): e3639.

12. O'Driscoll BR, Howard LS, Davison AG. BTS guideline for emergency oxygen use in adult patients. Thorax. 2008;63(Suppl 6):vi1-68.

13. Keenan SP, Sinuff T, Burns KE, Muscedere J, Kutsogiannis J, Mehta S, et al. Clinical practice guidelines for the use of noninvasive positive-pressure ventilation and noninvasive continuous positive airway pressure in the acute care setting. CMAJ. 2011;183(3):E195-214.

14. Parke RL, McGuinness SP. Pressures delivered by nasal high flow oxygen during all phases of the respiratory cycle. Respir Care. 2013;58(10):1621-4.

15. Groves N, Tobin A. High flow nasal oxygen generates positive airway pressure in adult volunteers. Aust Crit Care. 2007;20(4):126-31.

16. Douglas N, Ng I, Nazeem F, Lee K, Mezzavia P, Krieser R, et al. A randomised controlled trial comparing high-flow nasal oxygen with standard management for conscious sedation during bronchoscopy. Anaesthesia. 2018;73(2):169-76.

17. Schumann R, Natov NS, Rocuts-Martinez KA, Finkelman MD, Phan TV Hegde SR, et al. High-flow nasal oxygen availability for sedation decreases the use of general anesthesia during endoscopic retrograde cholangiopancreatography and endoscopic ultrasound. World J Gastroenterol. 2016:22(47):10398-405.

18. Marklund M, Verbraecken J, Randerath W. Non-CPAP therapies in obstructive sleep apnoea: mandibular advancement device therapy. Eur Respir J. 2012;39(5):1241-7.

19. Badiger S, John M, Fearnley RA, Ahmad I. Optimizing oxygenation and intubation conditions during awake fibre-optic intubation using a highflow nasal oxygen-delivery system. Br J Anaesth. 2015;115(4):629-32.

20. Sago T, Harano N, Chogyoji Y, Nunomaki M, Shiiba S, Watanabe S. A nasal high-flow system prevents hypoxia in dental patients under intravenous sedation. J Oral Maxillofac Surg. 2015;73(6):1058-64.

21. Lin Y, Zhang X, Li L, Wei M, Zhao B, Wang X, et al. High-flow nasal cannula oxygen therapy and hypoxia during gastroscopy with propofol sedation: a randomized multicenter clinical trial. Gastrointest Endosc. 2019;90(4):591-601.

22. Kim SH, Bang S, Lee KY, Park SW, Park JY, Lee HS, et al. Comparison of high flow nasal oxygen and conventional nasal cannula during gastrointestinal endoscopic sedation in the prone position: a randomized trial. Can J Anaesth. 2021;68(4):460-6.

23. Riccio CA, Sarmiento S, Minhajuddin A, Nasir D, Fox AA. High-flow versus standard nasal cannula in morbidly obese patients during colonoscopy: a prospective, randomized clinical trial. J Clin Anesth. 2019;54:19-24.

24. Thiruvenkatarajan V, Dharmalingam A, Arenas G, Wahba M, Liu WM, Zaw $Y$, et al. Effect of high-flow vs. low-flow nasal plus mouthguard oxygen therapy on hypoxaemia during sedation: a multicentre randomised controlled trial. Anaesthesia. 2021. https://doi.org/10.1111/anae.15527.

25. Moher D, Liberati A, Tetzlaff J, Altman DG. Preferred reporting items for systematic reviews and meta-analyses: the PRISMA statement. Ann Intern Med. 2009:151(4):264-9.

26. Teng WN, Ting CK, Wang YT, Hou MC, Chang WK, Tsou MY, et al. High-flow nasal cannula and mandibular advancement bite block decrease hypoxic events during sedative esophagogastroduodenoscopy: a randomized clinical trial. Biomed Res Int. 2019;2019:4206795.

27. Mazzeffi MA, Petrick KM, Magder L, Greenwald BD, Darwin P, Goldberg EM, et al. High-flow nasal cannula oxygen in patients having anesthesia for advanced esophagogastroduodenoscopy: HIFLOW-ENDO, a randomized clinical trial. Anesth Analg. 2021;132(3):743-51.

28. Nay MA, Fromont L, Eugene A, Marcueyz JL, Mfam WS, Baert O, et al. High-flow nasal oxygenation or standard oxygenation for gastrointestinal endoscopy with sedation in patients at risk of hypoxaemia: a multicentre randomised controlled trial (ODEPHI trial). Br J Anaesth. 2021:127(1):133-42.

29. Thiruvenkatarajan V, Dharmalingam A, Arenas G, Wahba M, Steiner R, Kadam VR, et al. High-flow nasal cannula versus standard oxygen therapy assisting sedation during endoscopic retrograde cholangiopancreatography in high risk cases (OTHER): study protocol of a randomised multicentric trial. Trials. 2020;21(1):444

30. Rostin P, Teja BJ, Friedrich S, Shaefi S, Murugappan KR, Ramachandran SK, et al. The association of early postoperative desaturation in the operating 
theatre with hospital discharge to a skilled nursing or long-term care facility. Anaesthesia. 2019;74(4):457-67.

31. Ritchie JE, Williams AB, Gerard C, Hockey H. Evaluation of a humidified nasal high-flow oxygen system, using oxygraphy, capnography and measurement of upper airway pressures. Anaesth Intensive Care. 2011;39(6):1103-10.

32. Sun YH, Dai B, Peng Y, Tan W, Zhao HW. Factors affecting FiO(2) and PEEP during high-flow nasal cannula oxygen therapy: a bench study. Clin Respir J. 2019;13(12):758-64.

33. Ricard JD, Roca O, Lemiale V, Corley A, Braunlich J, Jones P, et al. Use of nasal high flow oxygen during acute respiratory failure. Intensive Care Med. 2020;46(12):2238-47.

34. Wettstein RB, Shelledy DC, Peters JI. Delivered oxygen concentrations using low-flow and high-flow nasal cannulas. Respir Care. 2005;50(5):604-9.

35. McLellan E, Lam K, Behringer E, Chan V, Bozak D, Mitsakakis N, et al. Highflow nasal oxygen does not increase the volume of gastric secretions during spontaneous ventilation. Br J Anaesth. 2020;125(1):e75-80.

36. Patel A, Nouraei SA. Transnasal humidified rapid-insufflation ventilatory exchange (THRIVE): a physiological method of increasing apnoea time in patients with difficult airways. Anaesthesia. 2015;70(3):323-9.

37. Corso RM, Piraccini E, Agnoletti V, Lippi M, Buccioli M, Negro A, et al. Clinical use of the STOP-BANG questionnaire in patients undergoing sedation for endoscopic procedures. Minerva Anestesiol. 2012;78(1):109-10.

38. Wani S, Azar R, Hovis CE, Hovis RM, Cote GA, Hall M, et al. Obesity as a risk factor for sedation-related complications during propofol-mediated sedation for advanced endoscopic procedures. Gastrointest Endosc 2011;74(6):1238-47.

39. Berzin TM, Sanaka S, Barnett SR, Sundar E, Sepe PS, Jakubowski M, et al. A prospective assessment of sedation-related adverse events and patient and endoscopist satisfaction in ERCP with anesthesiologist-administered sedation. Gastrointest Endosc. 2011;73(4):710-7.

40. Liou SC, Hsu CM, Chen C, Su MY, Chiu CT. Assessment of the Berlin Questionnaire for evaluation of hypoxemia risk in subjects undergoing deep sedation for screening gastrointestinal endoscopy. Ther Clin Risk Manag. 2018;14:1331-6.

41. Cha B, Lee MJ, Park JS, Jeong S, Lee DH, Park TG. Clinical efficacy of highflow nasal oxygen in patients undergoing ERCP under sedation. Sci Rep. 2021;11(1):350.

42. Kim BK, Kim S, Kim CY, Cha J, Lee YS, Ko Y, et al. Factors associated with failure of high-flow nasal cannula. Respir Care. 2020;65(9):1276-84.

43. Cho J, Choi SM, Park YS, Lee CH, Lee SM, Yoo CG, et al. Prediction of cardiopulmonary events using the STOP-Bang questionnaire in patients undergoing bronchoscopy with moderate sedation. Sci Rep. 2020;10(1):14471.

44. Beitz A, Riphaus A, Meining A, Kronshage T, Geist C, Wagenpfeil S, et al. Capnographic monitoring reduces the incidence of arterial oxygen desaturation and hypoxemia during propofol sedation for colonoscopy: a randomized, controlled study (ColoCap Study). Am J Gastroenterol. 2012;107(8):1205-12.

45. Bautista A, Hrushka L, Lenhardt R. Procedural sedation in the morbidly obese: implications, complications, and management. Int Anesthesiol Clin. 2020;58(3):41-6.

46. Sarkar M, Niranjan N, Banyal PK. Mechanisms of hypoxemia. Lung India. 2017:34(1):47-60

47. Goligher EC, Slutsky AS. Not just oxygen? Mechanisms of benefit from high-flow nasal cannula in hypoxemic respiratory failure. Am J Respir Crit Care Med. 2017;195(9):1128-31.

48. Parke RL, Eccleston ML, McGuinness SP. The effects of flow on airway pressure during nasal high-flow oxygen therapy. Respir Care. 2011;56(8):1151-5.

49. Teng WN, Ting CK, Wang YT, Hou MC, Tsou MY, Chiang H, et al. Oral capnography is more effective than nasal capnography during sedative upper gastrointestinal endoscopy. J Clin Monit Comput. 2018;32(2):321-6.

50. Gedeon M, Gomes S, Roy K, Duclos-Miller P, Rose JS. Use of noninvasive positive pressure ventilation in patients with severe obesity undergoing esophagogastroduodenoscopy: a randomized controlled trial. Surg Obes Relat Dis. 2019;15(9):1589-94.

51. Bai Y, Xu Z, Chandrashekar M, St Jacques PJ, Liang Y, Jiang Y, et al. Comparison of a simplified nasal continuous positive airways pressure device with nasal cannula in obese patients undergoing colonoscopy during deep sedation: a randomised clinical trial. Eur J Anaesthesiol. 2019;36(9):633-40

\section{Publisher's Note}

Springer Nature remains neutral with regard to jurisdictional claims in published maps and institutional affiliations.
Ready to submit your research? Choose BMC and benefit from:

- fast, convenient online submission

- thorough peer review by experienced researchers in your field

- rapid publication on acceptance

- support for research data, including large and complex data types

- gold Open Access which fosters wider collaboration and increased citations

- maximum visibility for your research: over $100 \mathrm{M}$ website views per year

At BMC, research is always in progress.

Learn more biomedcentral.com/submissions 